\title{
Connexin 43 expression is associated with poor survival in patients with esophageal squamous cell carcinoma
}

\author{
TATSUYA TANAKA, MASAHIRO KIMURA, HIDEYUKI ISHIGURO, \\ KOUJI MIZOGUCHI and HIROMITSU TAKEYAMA \\ Department of Gastroenterological Surgery, Graduate School of Medical Sciences, \\ Nagoya University, Nagoya, Aichi 467-8601, Japan
}

Received October 2, 2015; Accepted March 7, 2016

DOI: $10.3892 / \operatorname{mco} .2016 .828$

\begin{abstract}
Connexin 43 (Cx43) is an important gap junction protein in vertebrates, which has been reported to function as a tumor suppressor in a number of organs. However, the mechanism underlying the effect of $\mathrm{Cx} 43$ on tumor progression remains unknown, with only a limited number of studies reporting on the role of $\mathrm{Cx} 43$ in esophageal cancer. In the present study, Cx43 expression was analyzed by immunohistochemical staining and the associations between $\mathrm{Cx} 43$ expression and clinicopathological characteristics or prognosis were evaluated. Cx43 was expressed at a high frequency in patients with esophageal squamous cell carcinoma (ESCC). Of the 98 ESCC cases investigated, positivity for $\mathrm{Cx} 43$ was observed in 62 cases (63.26\%). In patients with high Cx43 expression, the survival rates were significantly reduced compared with those in patients with low Cx43 expression. Moreover, the overexpression of Cx43, as measured by immunohistochemistry, was an independent prognostic indicator of ESCC. Thus, our data indicated that $\mathrm{Cx} 43$ may be a candidate molecular prognostic marker and molecular target for the development of an effective therapeutic intervention for patients with esophageal cancer.
\end{abstract}

\section{Introduction}

Esophageal squamous cell carcinoma (ESCC) is the sixth most common type of cancer in Japan, and ESCC-related mortality has been steadily increasing in recent years. ESCC is often diagnosed at an advanced stage, and the 5-year survival rate of patients who undergo curative surgery is only $20-30 \%$. In our hospital, we have encountered a number of patients who developed tumor recurrence or distant metastasis during the early stages of the disease, within a short period of time after

Correspondence to: Dr Masahiro Kimura, Department of Gastroenterological Surgery, Graduate School of Medical Sciences, Nagoya University, 1 Kawasumi, Mizuho-cho, Mizuho-ku, Nagoya, Aichi 467-8601, Japan

E-mail: mkimura@med.nagoya-cu.ac.jp

Key words: esophageal cancer, connexin 43, gap junction surgery. Recent molecular biological studies have revealed that esophageal cancer is caused by the accumulation of multiple genetic defects in dominant oncogenes and tumor suppressor genes. In order to elucidate the role of connexin 43 (Cx43) in ESCC, the expression status of Cx43 in patients with ESCC was evaluated (1-7). In addition, the associations between Cx43 expression and clinicopathological characteristics or prognosis were analyzed.

\section{Patients and methods}

Patients and tissue samples. Samples were obtained from 98 patients with primary ESCCs. The patients had undergone radical esophagectomy, without any preoperative induction therapy, at the Department of Surgery II, Nagoya City University Medical School (Nagoya, Japan) between 1997 and 2006. The study design was approved by the Institutional Review Board of our University, and written consent was obtained from all the patients. The tumors were classified according to the Guidelines for Clinical and Pathological Studies on Carcinoma of the Esophagus established by the Japanese Society for Esophageal Diseases (8). Tissue specimens were collected from 79 men and 19 women with a mean age of $63.5 \pm 8.3$ years (range, 46-78 years). Tissues collected for immunohistochemistry were fixed in formalin and embedded in paraffin.

Immunohistochemistry. Immunohistochemical staining was performed on formalin-fixed, paraffin-embedded ESCC tissues. The paraffin-embedded tumor sections were deparaffinized, rehydrated, heat-treated by microwaving in $10 \mathrm{mM}$ citrate buffer for $15 \mathrm{~min}$ for antigen retrieval, and cooled to room temperature. The sections were then treated with $0.3 \% \mathrm{H}_{2} \mathrm{O}_{2}$ in methanol for $30 \mathrm{~min}$ to neutralize endogenous peroxidase activity, blocked with Block Ace (DS Pharma Biomedical, Osaka, Japan) for $10 \mathrm{~min}$, and incubated with primary monoclonal anti-Cx43 antibody (cat. no. sc-59949; 1:500 dilution; Santa Cruz Biotechnology, Inc., Dallas, TX, USA) overnight at $4^{\circ} \mathrm{C}$. Immunoreactive protein was detected with a Dako EnVision+ System, horseradish peroxidase (substrate, diaminobenzidine) and the sections were counterstained with hematoxylin. Cx43 immunostaining was subjectively assessed by two independent investigators (T.T. and H.I.) using light microscopy. The intensity of Cx43 
Table I. Association between clinicopathological characteristics and connexin 43 expression.

\begin{tabular}{|c|c|c|c|c|}
\hline Characteristics & $\begin{array}{l}\text { Cases } \\
(\mathrm{n}=98)\end{array}$ & $\begin{array}{l}\text { High expression } \\
\qquad(\mathrm{n}=62)\end{array}$ & $\begin{array}{l}\text { Low expression } \\
\qquad(\mathrm{n}=36)\end{array}$ & P-value \\
\hline Age, years & & & & 1 \\
\hline$>65$ & 44 & 28 & 16 & \\
\hline$<65$ & 54 & 34 & 20 & \\
\hline Gender & & & & 0.792 \\
\hline Male & 79 & 49 & 30 & \\
\hline Female & 19 & 13 & 6 & \\
\hline \multicolumn{5}{|l|}{ Primary tumor } \\
\hline Tis & 1 & 0 & 1 & 0.00284 \\
\hline 1 & 31 & 12 & 19 & \\
\hline 2 & 15 & 13 & 2 & \\
\hline 3 & 25 & 19 & 6 & \\
\hline 4 & 26 & 18 & 8 & \\
\hline Tis-T2 & 47 & 25 & 22 & 0.06 \\
\hline $\mathrm{T} 3,4$ & 51 & 37 & 14 & \\
\hline Lymph node metastasis & & & & 0.397 \\
\hline Negative & 42 & 24 & 18 & \\
\hline Positive & 55 & 37 & 18 & \\
\hline Histological differentiation & & & & 0.481 \\
\hline High & 32 & 23 & 9 & \\
\hline Moderate & 52 & 31 & 21 & \\
\hline Poor & 14 & 8 & 6 & \\
\hline Lymphatic invasion & & & & 0.343 \\
\hline Positive & 72 & 48 & 24 & \\
\hline Negative & 26 & 14 & 12 & \\
\hline Venous invasion & & & & 0.281 \\
\hline Positive & 64 & 43 & 21 & \\
\hline Negative & 34 & 19 & 15 & \\
\hline
\end{tabular}

immunostaining was classified into 4 grades (0-3), where grades 0 and 1 were defined as low expression, and grades 2 and 3 were defined as high expression.

Statistical analysis. Statistical analysis was performed using the EZR software package (Saitama Medical Center, Jichi Medical University, Saitama, Japan). The Chi-square test was used to analyze the association between immunohistochemical analysis and the clinical and histopathological parameters of the patients. The survival of ESCC patients following surgery was assessed using the Kaplan-Meier method, and survival times were compared using the log-rank test. The data are expressed as mean \pm standard deviation. Multivariate analysis was performed using the Cox regression and logistic multivariate regression models. In all the analyses, P-values of $<0.05$ indicated statistically significant differences.

\section{Results}

Cx43 immunostaining. Of the 98 patients enrolled in this study, $62(63.3 \%)$ were high and $36(37.7 \%)$ were low for $\mathrm{Cx} 43$ expression. $\mathrm{Cx} 43$ expression was observed in epithelial, muscle and tumor cells. Representative cases of immunostaining are shown in Fig. 1.

Association between clinicopathological characteristics and Cx43 expression. The correlations between immunostaining for $\mathrm{Cx} 43$ and the clinicopathological characteristics of the patients are presented in Table I. No significant correlations were observed between $\mathrm{Cx} 43$ expression and clinicopathological characteristics such as age, gender, $\mathrm{T}$ status, $\mathrm{N}$ status, stage, lymphatic invasion, venous invasion and differentiation (Table I). We subsequently investigated the correlation between immunostaining for $\mathrm{Cx} 43$ and survival in patients with ESCC after surgery (median follow-up, 28 months). The patients in the $\mathrm{Cx} 43$-high group exhibited significantly shorter survival following surgery compared with patients in the Cx43-low group ( $\mathrm{P}=0.0188$, log-rank test; Fig. 2).

Uni- and multivariate analysis for clinicopathological variables of Cx43 expression. The univariate analysis revealed that, among the clinicopathological factors, tumor status [risk ratio $(\mathrm{RR})=6.399 ; \mathrm{P}<0.01]$, lymph node status $(\mathrm{RR}=4.358 ; \mathrm{P}<0.01)$, lymphatic invasion $(\mathrm{RR}=6.952 ; \mathrm{P}=0.001236)$, venous invasion 
Table II. Univariate analysis for clinicopathological variables of connexin 43 expression.

\begin{tabular}{lcc}
\hline Variables & Risk ratio & 95\% confidence interval \\
\hline Primary tumor & 1 & $3.025-13.54$ \\
Tis-T2 & 6.399 & \\
T3, 4 & 1 & $2.078-9.14$ \\
Lymph node metastasis & 4.358 & \\
Negative & 1 & $2.114-22.55$ \\
Positive & 6.952 & \\
Lymphatic invasion & 1 & $2.388-15.58$ \\
Negative & & \\
Positive & 6.099 & 0.01 \\
Venous invasion & 1 & $1.119-4.653$ \\
Negative & 2.282 & 0.001236 \\
Positive & & \\
Connexin 43 expression & & \\
Low & & \\
High & &
\end{tabular}

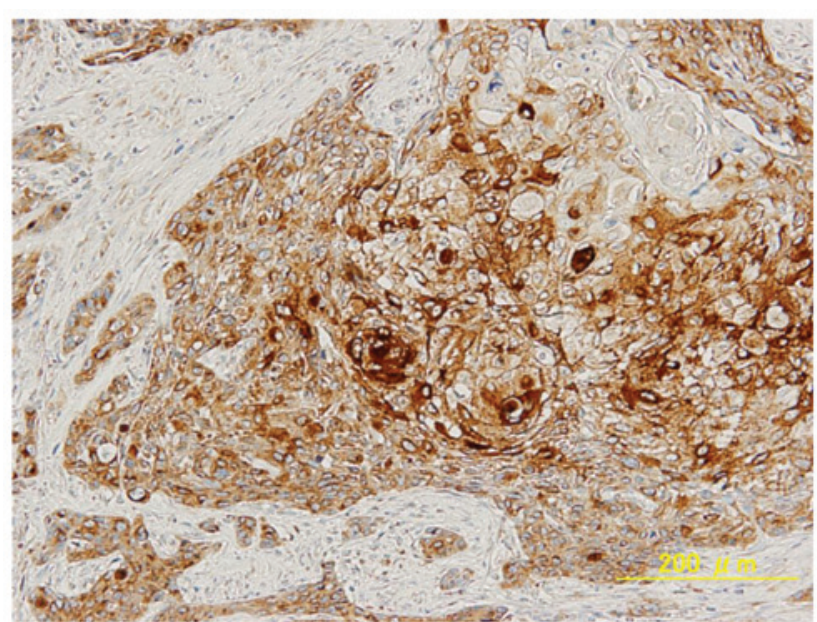

High expression

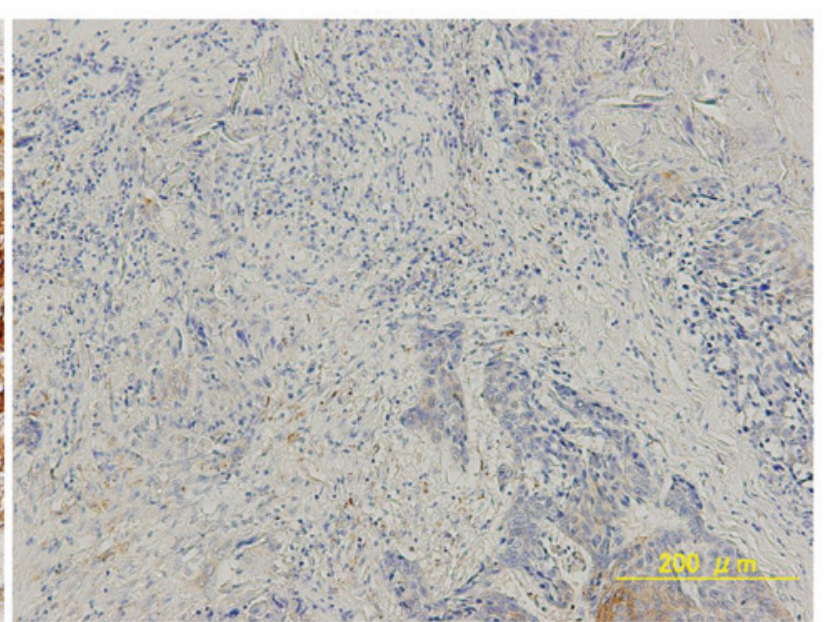

Low expression

Figure 1. Immunohistological analysis of esophageal cancer using anti-connexin 43 antibody staining. Magnification, x200.

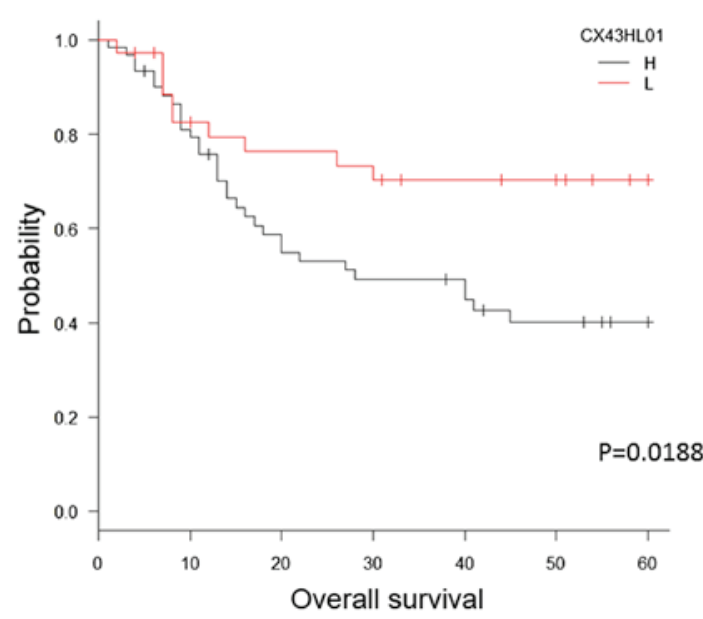

Figure 2. Survival rate of patients with esophageal squamous cell carcinoma. Cx43, connexin 43. H, high; L, low.
( $\mathrm{RR}=6.099 ; \mathrm{P}=0.000157)$ and $\mathrm{Cx} 43$ expression $(\mathrm{RR}=2.282$; $\mathrm{P}=0.02324)$ were all statistically significant prognostic factors (Table II). The multivariate analysis revealed that tumor status $(\mathrm{RR}=4.15 ; \mathrm{P}<0.01)$ and lymph node status $(\mathrm{RR}=3.213 ; \mathrm{P}=0.002)$ were independently associated with an unfavorable prognosis in patients with ESCC (Table III). The RR for CX43 was 2.017.

\section{Discussion}

Gap junctions, which were first described in the early 1960s, are cell membrane junctions responsible for intercellular communication, and are involved in tissue homeostasis, proliferation and differentiation. Disruption of this mechanism may facilitate the development of several disorders.

Cx proteins are involved in the function of gap junctions. Indeed, the primary function of $\mathrm{Cx}$ is to form conduits between 
Table III. Multivariate analysis for clinicopathological variables of connexin 43 expression.

\begin{tabular}{lcc}
\hline Variables & Risk ratio & 95\% confidence interval \\
\hline Primary tumor & 1 & $1.9220-8.959$ \\
Tis-T2 & 4.15 & \\
T3, & & \\
Lymph node metastasis & 1 & $1.498-6.888$ \\
Negative & 3.213 & \\
Positive & 1 & $0.1967-7.418$ \\
Lymphatic invasion & 1.208 & \\
Negative & 1 & 0.002 \\
Positive & 2.534 & $0.5968-10.760$ \\
Venous invasion & & \\
Negative & 1 & $0.8936-4.1701$ \\
Positive & 2.017 & 0.058 \\
Connexin 43 expression & & \\
Low & & \\
High & &
\end{tabular}

neighboring cells; these conduits mediate the intercellular exchange of small cytoplasmic molecules. Cxs constitute a family of structurally related transmembrane proteins that connect two adjacent cells by forming gap junctions. Each gap junction is composed of two hemichannels or connexons, and each connexon is composed of six Cx proteins. Cxs coordinate cell-to-cell communication by allowing the direct transfer of molecules $<1,000$ Daltons between cells. Over 20 types of Cxs have been identified to date. $\mathrm{Cx} 43$, which was the focus of this study, is expressed in the central nervous system, heart, bone and a number of other organs.

Several studies have demonstrated that $\mathrm{Cx}$ proteins often function as tumor suppressors (1-3). Additionally, Li et al previously reported the role of $\mathrm{Cx} 43$ in metastatic breast cancer cells (9). Their results demonstrated that the expression of $\mathrm{Cx} 43$ in breast cancer cells decreases the metastatic potential of the cells through a mechanism involving $\mathrm{N}$-cadherin expression and apoptosis, which is independent of gap junctional communication. In non-small-cell lung cancer, reduced expression of $\mathrm{Cx} 43$ and E-cadherin has been found to be significantly correlated with poor differentiation, advanced TNM stage and lymph node metastasis, suggesting that concurrent reduction of $\mathrm{Cx} 43$ and E-cadherin expression may contribute to the development of lung cancer (10). Thus, Cx43 may induce E-cadherin expression, thereby inhibiting cell proliferation and lung cancer progression. In a study on Cx43 in colon cancer, Ismail et al analyzed the expression of $\mathrm{Cx} 43$ in samples from 80 cases of histopathologically confirmed and clinically diagnosed human colon cancer and in adjacent control tissues, and assessed the correlations with the clinicopathological variables (11). The expression of Cx43 was found to be significantly downregulated (75\%) in cancer samples compared with that in adjacent control tissues. Moreover, $\mathrm{Cx} 43$ downregulation was significantly associated with histological type and tumor invasion properties of the cancer. Additionally, Bigelow et al performed gap junction activity assays and protein analysis to evaluate the effects of Cx43 overexpression in SW480 human colorectal cancer cells (2) and demonstrated that overexpression of $\mathrm{Cx} 43$ in SW480 cells led to a 6-fold increase in gap junctional activity compared with that in controls.

In contrast to the abovementioned reports, other studies have suggested that $\mathrm{Cx} 43$ may act as an oncogene (12). Ogawa et al investigated the expression of $\mathrm{Cx} 43$ in rat hepatocellular carcinoma cells (13) and found that suppression of Cx43 expression in tumor cells reduced the migration and invasion capacity of the cells in vitro and the metastatic ability of the cells in vivo, indicating that $\mathrm{Cx} 43$ may have potential as a molecular target for the prevention of cancer metastasis in $\mathrm{Cx} 43$-overexpressing tumors. Thus, while $\mathrm{Cx} 43$ is often reported to function as a tumor suppressor, differential functions may be observed in the context of different tissue types.

In esophageal cancer, the role of $\mathrm{Cx} 43$ has not been sufficiently investigated. Garber et al (7) previously analyzed the expression of $\mathrm{Cx} 43$ in neoplastic esophageal epithelial cells in rats. However, the association between $\mathrm{Cx} 43$ expression and the clinicopathological characteristics of ESCC has not been previously described. In this study, we aimed to determine the clinicopathological significance of $\mathrm{Cx} 43$ expression in ESCC; three main findings were noted: First, Cx43 was expressed at a high frequency in patients with ESCC. Of the 98 ESCC cases, positivity for Cx43 was observed in 62 cases. Second, the survival of patients with high $\mathrm{Cx} 43$ expression was significantly poorer compared with that of patients with low Cx43 expression. Third, overexpression of Cx43, as measured by immunohistochemistry, was an independent prognostic indicator in patients with ESCC.

In summary, the prognosis of patients with esophageal cancer remains poor. Therefore, it is crucial to identify prognostic factors for patients with this disease. Several genes have been reported as prognostic factors in patients with esophageal cancer. Our data indicated that $\mathrm{Cx} 43$ may be a 
candidate molecular prognostic marker and molecular target for the development of an effective therapeutic intervention for patients with esophageal cancer.

\section{References}

1. Solan JL and Lampe PD: Specific Cx43 phosphorylation events regulate gap junction turnover in vivo. FEBS Lett 17: 1423-1429, 2014.

2. Bigelow $\mathrm{K}$ and Nguyen TA: Increase of gap junction activities in SW480 human colorectal cancer cells. BMC Cancer 14: 502, 2014.

3. Tang B, Peng ZH, Yu PW, Yu G, Qian F, Zeng DZ, Zhao YL, Shi Y, Hao YX and Luo HX: Aberrant expression of Cx43 is associated with the peritoneal metastasis of gastric cancer and $\mathrm{Cx} 43$-mediated gap junction enhances gastric cancer cell diapedesis from peritoneal mesothelium. PLoS One 8: e74527, 2013.

4. de Oliveira KD, Tedardi MV, Cogliati B and Dagli ML: Higher incidence of lung adenocarcinomas induced by DMBA in connexin 43 heterozygous knockout mice. Biomed Res Int 2013: 618475,2013

5. Yi ZC, Wang H, Zhang GY and Xia B: Downregulation of connexin 43 in nasopharyngeal carcinoma cells is related to promoter methylation. Oral Oncol 43: 898-904, 2007.

6. Uzu M, Sato H, Yamada R, Kashiba T, Shibata Y, Yamaura K and Ueno K: Effect of enhanced expression of connexin 43 on sunitinib-induced cytotoxicity in mesothelioma cells. J Pharmacol Sci 128: 17-26, 2015
7. Garber SA, Fernstrom MJ, Stoner GD and Ruch RJ: Altered gap junctional intercellular communication in neoplastic rat esophageal epithelial cells. Carcinogenesis 18: 1149-1153, 1997.

8. Japanese Esophageal Society: Japanese Classification of Esophageal Cancer. 10th edition. Kanehara \& Co., Ltd., Tokyo, 2008.

9. Li Z,Zhou Z, Welch DR and Donahue HJ: Expressing connexin 43 in breast cancer cells reduces their metastasis to lung. Clin Exp Metastasis 25: 893-901, 2008.

10. Xu HT, Li QC, Zhang YX, Zhao Y, Liu Y, Yang ZQ and Wang EH: Connexin 43 recruits E-cadherin expression and inhibits the malignant behavior of lung cancer cells. Folia Histochem Cytobiol 46: 315-321, 2008.

11. Ismail R, Rashid R, Andrabi K, Parray FQ, Besina S, Shah MA and Ul Hussain M: Pathological implications of $\mathrm{Cx} 43$ down-regulation in human colon cancer. Asian Pac J Cancer Prev 15: 2987-2991, 2014.

12. Zhang A,Hitomi M,Bar-Shain N,Dalimov Z, Ellis L, Velpula KK, Fraizer GC, Gourdie RG and Lathia JD: Connexin 43 expression is associated with increased malignancy in prostate cancer cell lines and functions to promote migration. Oncotarget 10: 11640-11651, 2015.

13. Ogawa K, Pitchakam P, Suzuki S, Chewonarin T, Tang M, Takahashi S, Naiki-Ito A, Sato S, Takahashi S, Asamoto M and Shirai T: Silencing of connexin 43 supresses invasion, migration and lung metastasis of rat hepatocellular carcinoma cells. Cancer Sci 103: 860-867, 2012. 